\title{
Prevalence of Visceral Adhesions in Sockeye Salmon, Oncorhynchus nerka, in the Central North Pacific Ocean
}

\author{
Kazuya NagASAWA* \\ Hokkaido Fisheries Experimental Station, \\ 2-6, Hama-cho, Kushiro, Hokkaido 085, Japan
}

\begin{abstract}
A shipboard survey was undertaken to determine the prevalence of visceral adhesions in sockeye salmon, Oncorhynchus nerka, in the central North Pacific Ocean in the spring and early summer of 1981-1983. Of 3,935 sockeye from 49 locations examined, $206(5.2 \%)$ were affected. Although no adhesions were observed in fish less than $30 \mathrm{~cm}$ in fork length, prevalence increased in medium-sized fish. Visceral adhesions were most common among fish between 35 and $49 \mathrm{~cm}$. In fish above $50 \mathrm{~cm}$, however, the proportion of affected fish decreased with increasing fish size. No adhesions occurred in fish of $65 \mathrm{~cm}$ and larger.

A close relationship between prevalence and fish age was noted. Prevalence increased steadily with increasing freshwater age ( 0 -winter, $0 \%$; 1-winter, $4.1 \%$; 2-winter, $6.3 \%$; 3-winter, $11.0 \%$ ). As to ocean age, prevalence was highest $(6.9 \%)$ in fish which had spent two winters at sea, but was at a low level in fish of each of other ages (1-winter, $1.4 \% ; 3$-winter, $1.2 \%$; 4-winter, $0 \%$ ).

The percentage of affected fish was higher in males $(7.9 \%)$ than in females $(2.7 \%)$. This was stable among years and most fishing locations. Adhesions also occurred most often in immature fish (male, $9.4 \%$; female, $4.2 \%$ ). With developing fish maturation, prevalence decreased and reached null in both sexes when fish were mature.

Prevalence varied latitudinally, declining from south to north in general. This was reflected by latitudinal changes in the size and maturity compositions of fish. In the areas between $42^{\circ}$ and $47^{\circ} \mathrm{N}$, most catches consisted of immature medium-sized fish, in which adhesions were often observed. In the areas between $48^{\circ}$ and $51^{\circ} \mathrm{N}$, however, fish were large and maturing, and adhesions were rarely found in them.
\end{abstract}

\section{Introduction}

Sockeye salmon, Oncorhynchus nerka (WALBAUM), are widely distributed in the northern North Pacific Ocean and adjacent seas. They are major objects of coastal and high-seas fisheries and have been heavily exploited. While a volume of information has been accumulated on many aspects of their biology (see FOERSTER, 1968), little is known concerning diseases during their ocean life.

FRENCH (1965) first reported the occurrence of visceral adhesions in Pacific salmon captured on the high seas. He found visceral adhesions most often in sockeye salmon and rarely in chum salmon, Oncorhynchus keta (WALBAUM). MARGOLIS (1970)

* Present address: Hokkaido Fisheries Experimental Station, 1-2-66 Yunokawa-cho, Hakodate, Hokkaido 042, Japan. also mentioned that visceral adhesions occurred in high-seas sockeye salmon.

Visceral adhesions are associated with the infections of a dracunculoid nematode, Philonema oncorhynchi KUITUNEN-EKBAUM. This is a parasite of the body cavity of salmonids in the North Pacific region of both American and Asian sides (e.g., Kuitunen-Ekbaum, 1933; Bangham and Adams, 1954; AKHMEROV, 1955; MARgolis, 1963; KonOvalov, 1971). Although it is commonly found in high-seas sockeye salmon (MARGOLIS, 1963), it is actually a freshwater parasite using a copepod, Cyclops bicuspidatus, as its intermediate host (Platzer and Adams, 1967; Ko and Adams, 1969). Young sockeye salmon get infected by feeding on $C$. bicuspidatus during their lake residence. The nematode larvae develop slowly in the tissues during the sockeye's ocean life and move from the tissues to the body cavity prior to the host's homeward 
migration. Visceral adhesions are induced by the host reaction associated with this movement. Platzer and Adams (1967) reported that sockeye salmon infected with $P$, oncorhynchi developed visceral adhesions in the laboratory. MARGoLis (1970. 1982) briefly reviewed the life cycle of $P$ oncorhynchi and visceral adhesions in sockeye salmon.

Under the cooperative program of the International North Pacific Fisheries Commission. Japan, Canada and the United States have conducted research to clarify the distribution, abundance, and continent of origin of Pacific salmon in the North Pacific Ocean and Bering Sea. The RV Hokushin maru of the Hokkaido Fisheries Experimental Station has been engaged in such salmon research every year as a member of Japanese research vessels. When I was on board the Hokushin maru in the spring and early summer of 1981-1983. I examined the occurrence of sockeye salmon with visceral adhesions in the gillnet catches. This paper deals with the prevalence of visceral adhesions in high-seas sockeye salmon from the central North Pacific Ocean in relation to the size, age, sex and maturity of fish and the fishing location.

\section{Materials and Methods}

Sockeye salmon were sampled at 49 locations in the central North Pacific Ocean during the cruises of the RV Hokushin maru in July 1981. May and June 1982, and May and June 1983. The fishing locations were distributed over a wide area south of the central Aleutian Islands (Fig. 1). Fish were captured with gillnets, which consisted of two types; non-selective research gillnets which were composed of 10 different mesh sizes from 48 to $157 \mathrm{~mm}$ to eliminate the mesh selectivity (TAK^GI, 1975) and commercial gillnets (mesh sizes 112 and $116 \mathrm{~mm}$ ).

Fish were measured (fork length) and weighed. They were opened. sexed and examined for the presence of visceral adhesions. Gonad weights were recorded and scale samples were also collected for subsequent age determination.

Ages of fish were recorded according to the European formula (Koo, 1962): the numeral preceding a dot (freshwater age) represents the number of winters spent in fresh water after hatching. and the numeral following a dot (ocean age) shows the number of winters spent in the sea. Based on

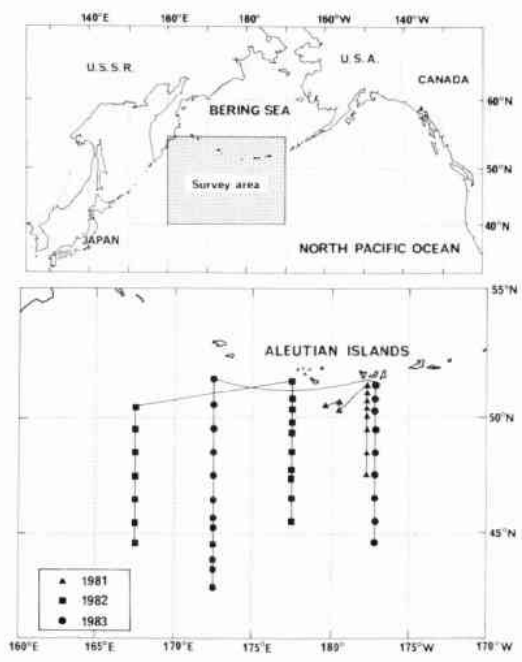

Fig. 1. Cruise tracks of the RV Hokushin maru and fishing locations of sockeye salmon examined for visceral adhesions in 1981-1983.

gonad weight data, the maturity of fish was assigned to one of the following four stages: immature. maturing I, maturing 11 and maturing III. Maturing fish were those fish destined to spawn in the year of catch and immatures were those fish which would have remained in the sea one or more winters if they had not been caught. The differentiation of immature and maturing fish was made using the gonad weight criteria established by TAKAGI (1961) and OsAKo (1973), and new criteria were used for the separation of the three maturing stages. The new criteria were developed by the staft of the Far Seas Fisheries Research Laboratory. Shimizu, Japan.

\section{Results}

The gross appearance of visceral adhesions in sockeye salmon was the same as that described by FRENCH (1965). Visceral organs and gonads were tightly bound and compacted to a mass. They were surrounded by a thick connective tissue sheath. which adhered to the peritoneum of the body wall (Fig. 2). There were no external differences between fish with adhesions and normal fish. 


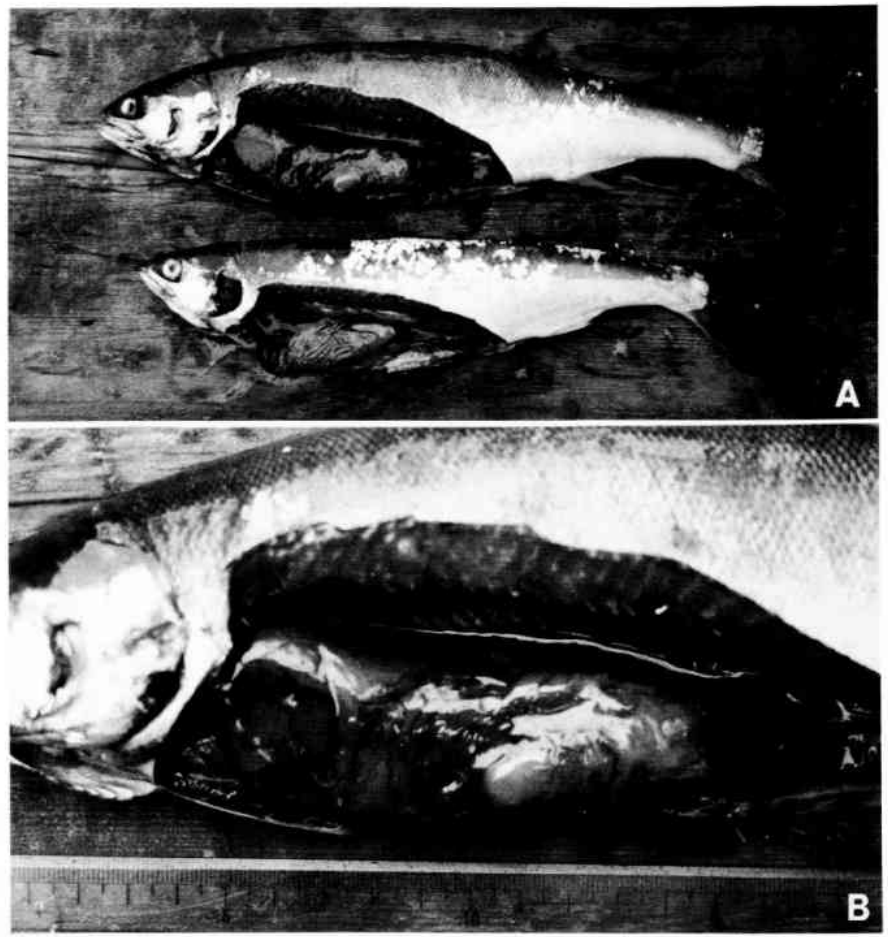

Fig. 2. Visceral adhesions in sockeye salmon. A: Fish with visceral adhesions (top) and normal fish (bottom). B: Visceral organs and gonads are enveloped by a thick connective tissue sheath.

During the period 1981 to 1983, a total of 3.935 sockeye salmon captured in the central North Pacific Ocean were examined and $206\left(5.2^{\circ}{ }_{0}\right)$ of these were affected with visceral adhesions. The proportion of affected fish was relatively stable among the three years, ranging from 4.0 to $6.9^{\circ}$ \% (Table 1). Diseased fish were distributed throughout the sampling area, as indicated by the fact that visceral adhesions were found at 41 of $49(83.7 \%)$ fishing locations.

There were marked differences in prevalence between sexes of fish (Table 1). Males were more often affected than females. Prevalence in males was also higher than that in females at 35 of $41(85.4 \%)$ locations.
Table 1. Prevalence of visceral adhesions in sockeye salmon in the central North Pacific Ocean. $1981-1983$

\begin{tabular}{cccc}
\hline \hline Year & Male & Female & Total \\
\hline 1981 & $58883(6.6)^{*}$ & $26 / 817(3.2)$ & $84 / 1700(4.9)$ \\
1982 & $32.545(5.9)$ & $11 / 541(2.0)$ & $43 / 1086(4.0)$ \\
1983 & $69764(9.0)$ & $10 / 385(2.6)$ & $79 / 1149(6.9)$ \\
\hline Total & $159 / 2192(7.3)$ & $47 / 1743(2.7)$ & $206 / 3935(5.2)$
\end{tabular}

* Number with visceral adhesions/number examined (percent). 
Table 2. Prevalence of visceral adhesions in sockeye salmon by age in the central North Pacific Ocean, 1981-1983

\begin{tabular}{lcccc}
\hline \hline Age group & 1981 & 1982 & 1983 & Total \\
\hline $0.1^{* *}$ & - & $0 / 1(0)^{*}$ & - & $0 / 1(0)$ \\
1.1 & $1 / 29(3.4)$ & $0 / 17(0)$ & $0 / 17(0)$ & $1 / 63(1.6)$ \\
2.1 & $1 / 10(10.0)$ & $0 / 26(0)$ & $0 / 25(0)$ & $1 / 61(1.6)$ \\
3.1 & - & $0 / 2(0)$ & $0 / 7(0)$ & $0 / 9(0)$ \\
$X .1^{* * *}$ & $0 / 4(0)$ & $0 / 1(0)$ & $0 / 6(0)$ & $0 / 11(0)$ \\
0.2 & $0 / 2(0)$ & $0 / 3(0)$ & $0 / 1(0)$ & $0 / 6(0)$ \\
1.2 & $45 / 967(4.7)$ & $11 / 182(6.0)$ & $23 / 322(7.1)$ & $79 / 1471(5.4)$ \\
2.2 & $21 / 422(5.0)$ & $22 / 194(11.3)$ & $34 / 273(12.5)$ & $77 / 889(8.7)$ \\
3.2 & $0 / 8(0)$ & $1 / 7(14.3)$ & $7 / 39(17.9)$ & $8 / 54(14.8)$ \\
$X .2$ & $9 / 92(9.8)$ & $1 / 15(6.7)$ & $2 / 28(7.1)$ & $12 / 135(8.9)$ \\
0.3 & - & $0 / 12(0)$ & $0 / 6(0)$ & $0 / 18(0)$ \\
1.3 & $0 / 33(0)$ & $2 / 279(0.7)$ & $2 / 195(1.0)$ & $4 / 507(0.8)$ \\
2.3 & $0 / 32(0)$ & $3 / 215(1.4)$ & $2 / 121(1.7)$ & $5 / 368(1.4)$ \\
3.3 & $0 / 2(0)$ & $2 / 20(10.0)$ & $0 / 6(0)$ & $2 / 28(7.1)$ \\
$X .3$ & $0 / 2(0)$ & $0 / 28(0)$ & $1 / 31(3.2)$ & $1 / 61(1.6)$ \\
0.4 & - & $0 / 8(0)$ & $0 / 1(0)$ & $0 / 1(0)$ \\
1.4 & - & $0 / 2(0)$ & $0 / 9(0)$ & $0 / 17(0)$ \\
2.4 & - & $1 / 71(1.4)$ & $0 / 2(0)$ & $0 / 4(0)$ \\
$X .4$ & - & $0 / 3(0)$ & $0 / 1(0)$ & $0 / 1(0)$ \\
$X . X$ & $1 / 10(10.0)$ & $6 / 51(11.8)$ & $13 / 209(6.2)$ \\
- & $-* *$ & & $2 / 8(25.0)$ & $3 / 21(14.3)$ \\
\hline
\end{tabular}

* Number with visceral adhesions/number examined (percent).

** Freshwater age preceds a dot, and ocean age follows a dot.

*** Undetermined age is expressed by $\mathrm{X}$.

**** Scales for age determination were not collected.

No adhesions were detected in fish less than $30 \mathrm{~cm}$ in fork length. There was a marked increase in the prevalence in medium-sized fish. Visceral adhesions were most common among fish between the lengths of 35 and $49 \mathrm{~cm}$. In fish above $50 \mathrm{~cm}$, however, the percentage of afflicted fish decreased with increasing size of fish. No fish of $65 \mathrm{~cm}$ and larger had visceral adhesions (Fig. 3).

Fifteen age groups were recognized during this study. Of these, age 3.2 fish were most frequently affected. Prevalence in this group was highest in 1982 and 1983, although in 1981 no adhesions were found possibly because of the small sample size. The second highest prevalence was observed in age 2.2 fish. Fish of ages 1.2 and $3.3 \mathrm{had}$ also relatively high prevalences (Table 2 ).

The proportion of affected fish increased sharply with increasing length of stay in fresh water (Fig. 4). Visceral adhesions did not occur in age 0 . fish. Prevalences in fish of ages 1 . and 2. were 4.1 and $6.3 \%$, respectively, and the rate reached a high of
$11.0 \%$ in age 3 . fish.

On the other hand, the percentage of afflicted fish increased markedly from $1.4 \%$ in age .1 fish to $6.9 \%$ in age .2 fish. However, prevalence decreased to $1.2 \%$ in age .3 fish and adhesions were absent in age .4 fish (Fig. 4).

The occurrence of visceral adhesions was closely related to fish maturity (Fig. 5). Visceral adhesions occurred most frequently in immature fish of both sexes, except for females in 1981. The overall percentages of immature affected males and females during 1981 and 1983 were 9.4 and $4.2 \%$, respectively. In maturing fish, however, there was a sharp decrease in prevalence, which declined with proceeding maturation of fish. In maturing-I fish, the combined prevalence in each sex among the years was $6.7 \%$ in males and $1.8 \%$ in females. Only three of $502(0.6 \%)$ maturing-II fish had visceral adhesions and no adhesions were observed in 147 maturing-III fish.

Although the proportion of affected fish was high 

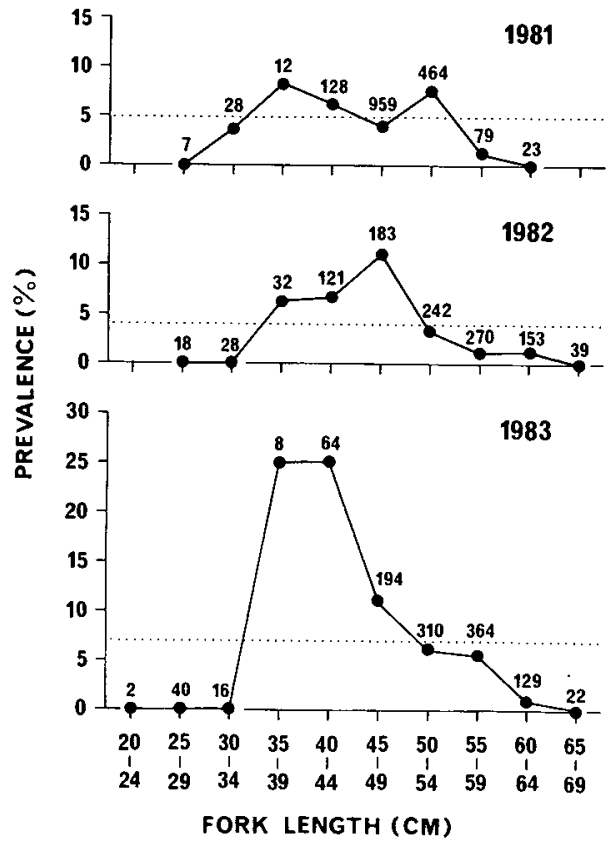

Fig. 3. Prevalence of visceral adhesions in relation to size of sockeye salmon in the central North Pacific Ocean, 1981-1983. Numerals refer to the number of fish. The dotted horizontal line indicates a prevalence level of each year.

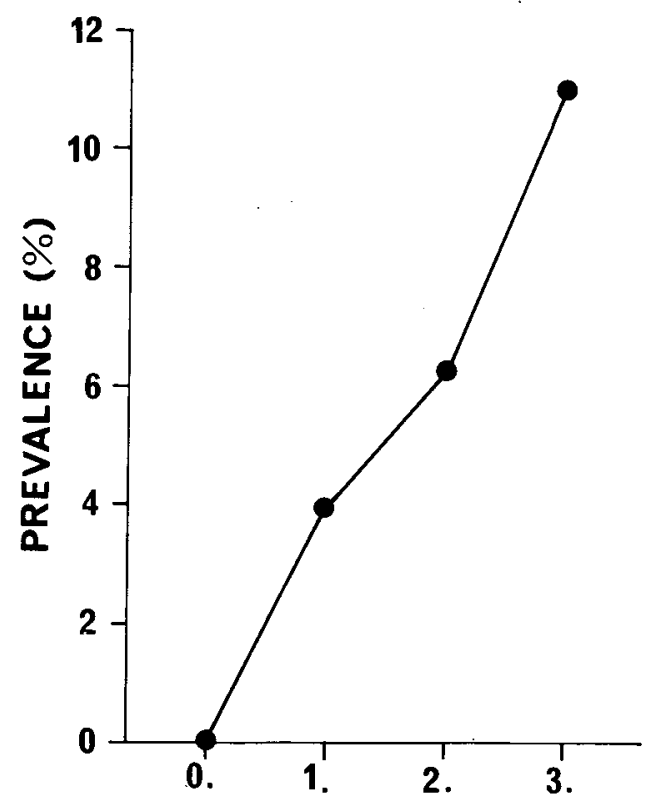

FRESHWATER AGE between $50^{\circ}$ and $51^{\circ} \mathrm{N}$ along $177^{\circ} 30^{\prime} \mathrm{W}$ in 1983 , prevalence generally decreased from south to north (Fig. 6). This was reflected by latitudinal changes in the size and maturity compositions of fish. Except for $177^{\circ} 30^{\prime} \mathrm{W}$ in 1981, small- and medium-sized fish predominated between $42^{\circ}$ and $47^{\circ} \mathrm{N}$. The majority of these fish were immature or maturing I. However, the percentage of large and maturing-II or -III fish increased northward to $51^{\circ} \mathrm{N}$ (Figs. 7 and 8). Since visceral adhesions occurred most often in immature medium-sized fish, higher prevalences in the southern regions were due to the restricted distribution of such fish in those areas.

\section{Discussion}

During the period 1981 to 1983 , the prevalence of visceral adhesions in central North Pacific sockeye salmon was relatively stable, ranging from 4.0 to $6.9 \%$. FRENCH (1965) reported that the percentage of affected sockeye captured on the high seas ranged from 0 to $25 \%$ between 1957 and 1964 and it increased markedly from $0-2 \%$ in $1957-1962$ to $9-25 \%$ in $1963-1964$. He mentioned that the frequency of occurrence of afflicted fish in 1963-1964

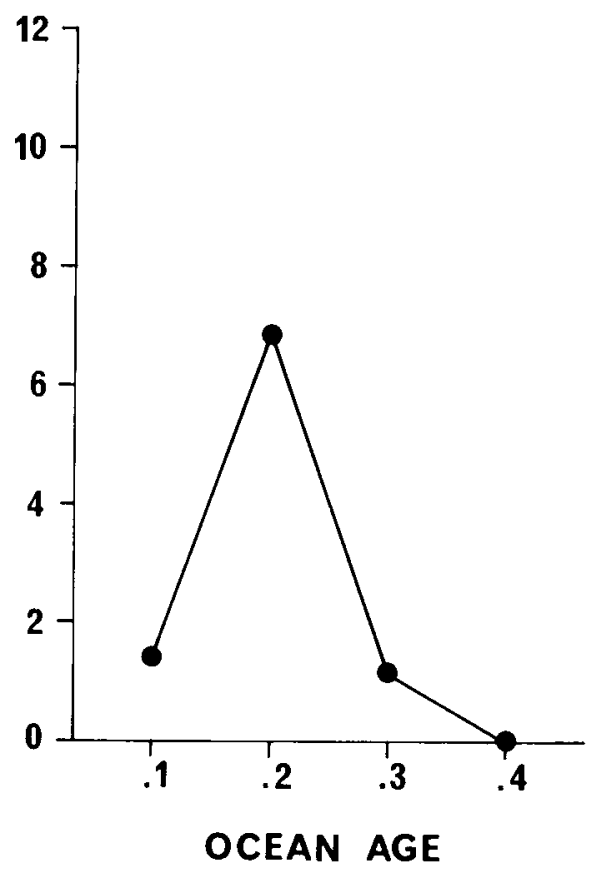

Fig. 4. Prevalence of visceral adhesions in relation to freshwater age (left) and ocean age (right) of sockeye salmon in the central North Pacific Ocean, 1981-1983. Data were taken from Table 2. 

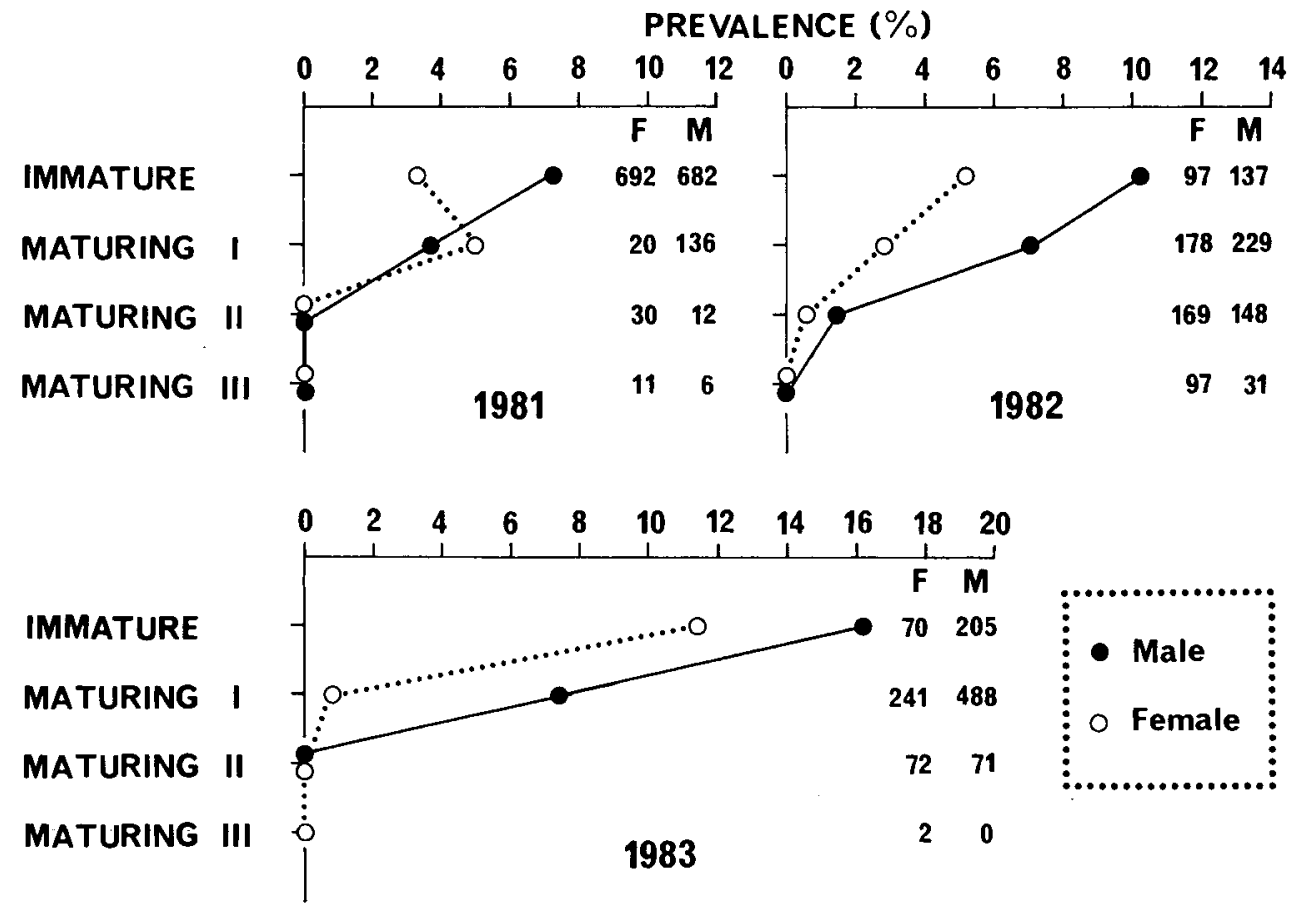

Fig. 5. Prevalence of visceral adhesions in relation to maturity of sockeye salmon in the central North Pacific Ocean, 1981-1983. Numerals refer to the number of fish of each sex (F, female; $\mathrm{M}$, male).

PREVALENCE (\%)

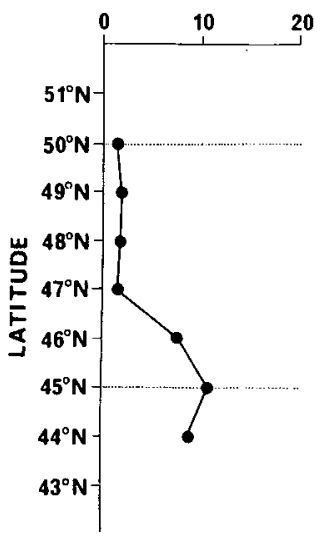

LONGITUDE : $\quad 167^{\circ} 30^{\prime} \mathrm{E}$

DATE : MAY 1982

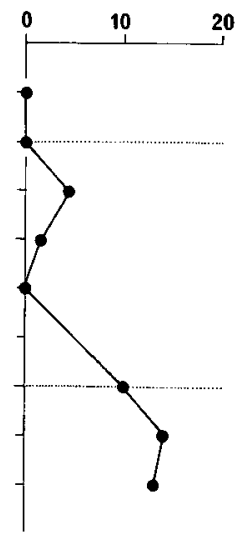

$172^{\circ} 30^{\prime} \mathrm{E}$

MAY 1983

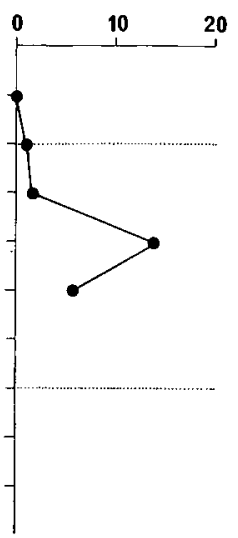

$177^{\circ} 30^{\prime} \mathrm{E}$

MAY - JUNE 1982
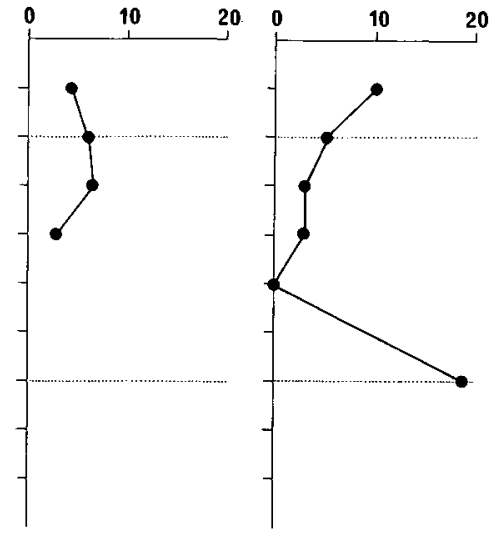

$177^{\circ} 30^{\prime} \mathrm{W}$

MAY-JUNE 1983

Fig. 6. Latitudinal changes in the prevalence of visceral adhesions in sockeye salmon in the central North Pacific Ocean, 1981-1983. Sample sizes are given in Fig. 7. Samples under 10 were excluded. 


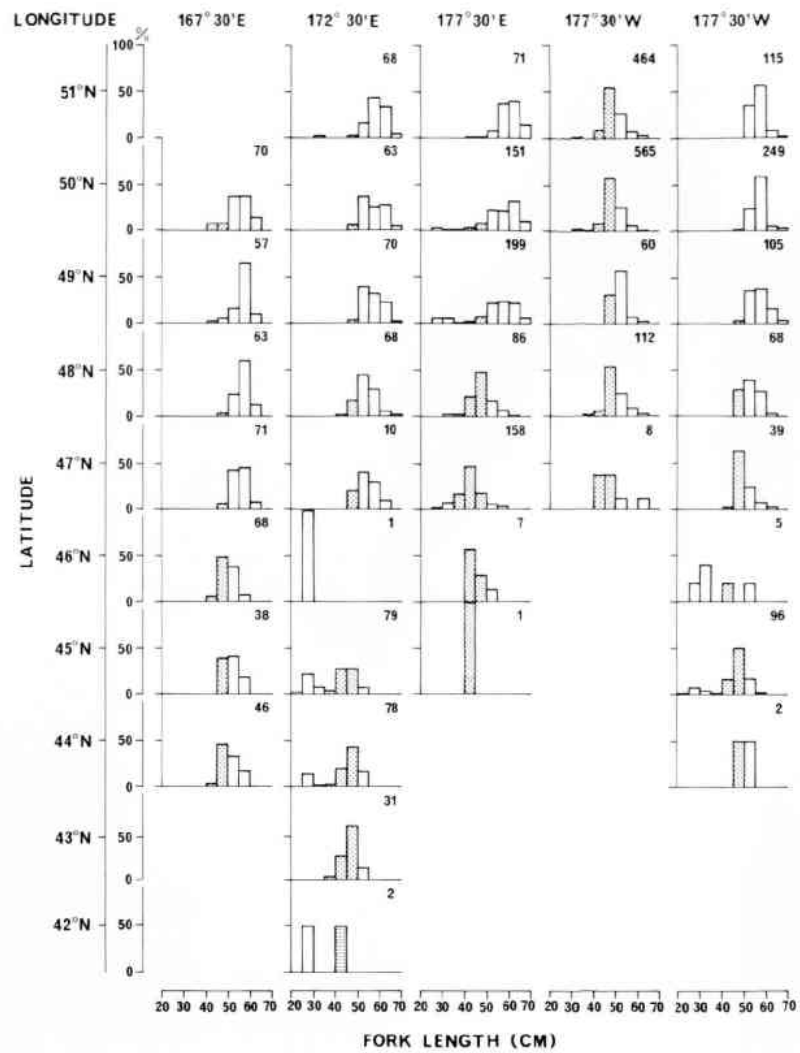

Fig. 7. Latitudinal changes in the size frequency distribution of sockeje salmon in the central North Pacific Ocean. Numerals refer to the number of fish. Stippled areas indicate fish between 35 and $49 \mathrm{~cm}$ long.

represented a true increase. This suggests that prevalence fluctuates year by year. The present study, however, revealed that prevalence was closely related to the size, age, sex and maturity of fish. Thus, biological data of samples are needed for an accurate comparison of prevalence levels. In addition, maturity of fish changes with season and size (age) and maturity compositions vary from place to place. Date and location of capture should be considered when prevalence data are compared.

The proportion of affected fish increased with increasing freshwater life of fish. This is probably because the longer young sockeye salmon stay in the lake, the more heavily they become infected with Philonema oncorhynchi through ingestion of its intermediate hosts. As visceral adhesions result from the host reaction associated with the migration of the parasite, the higher prevalence in fish of longer freshwater stay indicates that heavy infections of $P$. oncorhynchi raise marked host reaction.

The occurrence of visceral adhesions was sexrelated, with male sockeye having a higher pre- 


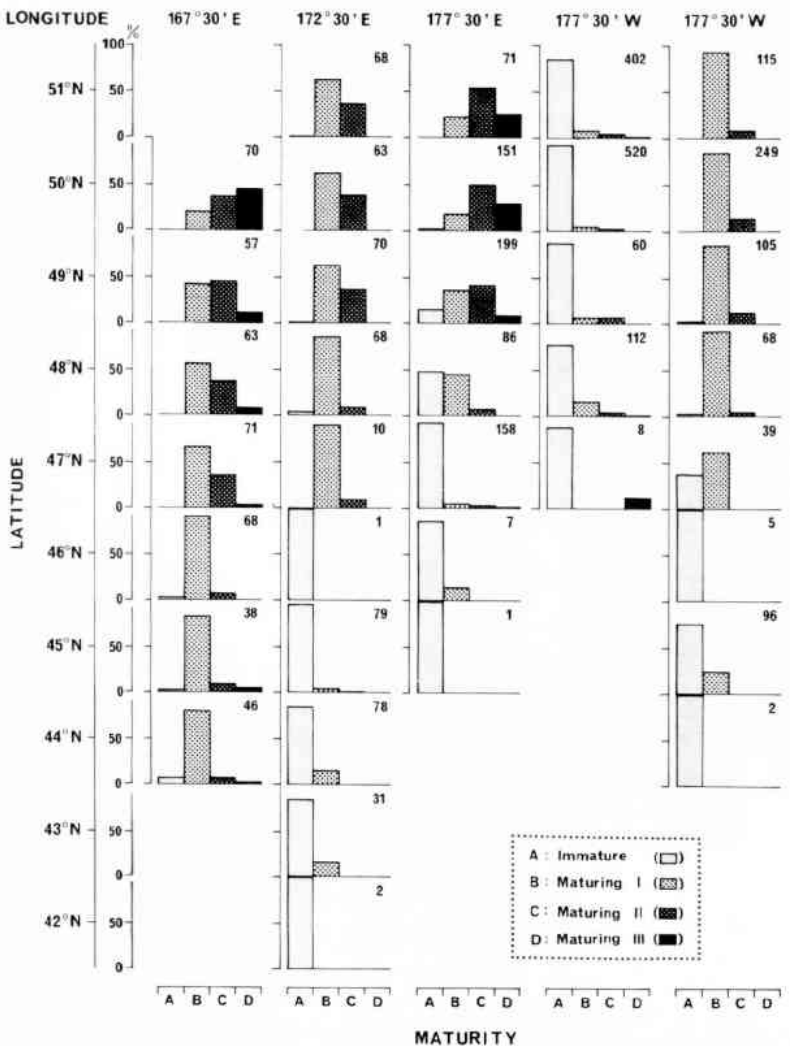

Fig. 8. Latitudinal changes in the maturity composition of sockeye salmon in the central North Pacific Ocean. Numerals refer to the number of fish.

valence than females. Similar observations were made by FRENCH (1965). Since the intake of intermediate hosts of $P$. oncorhynchi seems to be equall between both sexes of fish. there must be no differences in parasite burdens between them. Thus, the disparity in prevalences between sexes suggests that the host reaction to migrating $P$. oncorhynchi is related not only to the intensity of the infection but also to other factors such as host sex hormones. Furthermore, the timing of migration of $P$. oncorhynchi from the tissues to the body cavity may be different between sexes.
The prevalence of visceral adhesions decreased with growth, ocean age, and maturation of sockeye salmon. This phenomenon indicates that visceral adhesions disappear with these processes or affected fish die in the ocean. Margotis (1970) suggested that since visceral adhesions were not found in mature fish. the condition is transitory. Platzer and ADAMS (1967) made a similar suggestion. MARGOLIS also mentioned that there seems to be no mortality of affected fish. However. whether visceral adhesions cause ocean mortality of sockeye salmon is not known. FrencH (1965) 
mentioned that if salmon with adhesions die before reaching maturity, the adhesions could be a natural mortality factor. Recently, BELL and MARGOLIS (1976) reported that the survival of progeny of sockeye salmon was partially affected by the intensity of infection of female parent with $P$. oncorhynchi. The impact of visceral adhesions on sockeye populations remains still obscure, and further study is needed to clarify the effects of visceral adhesions on sockeye salmon.

\section{Acknowledgements}

I wish to express my sincere gratitude to $\mathrm{Mr}$. $\mathrm{H}$. Kondo, Mr. J. Nakata and Mr. Y. Imai of the Hokkaido Fisheries Experimental Station for their interest and encouragement. I am also grateful to the staff of the Far Seas Fisheries Research Laboratory, Fisheries Agency of Japan, for their valuable advice. Thanks are due to the crew of the RV Hokushin maru for their assistance on board.

\section{References}

Akhmerov, A. KH. (1955): Parasite fauna of Kamchatka River fishes. Izv. Tikhookean. Nauchno-Issled. Inst. Rybn. Khoz. Okeanogr., 43, 99-137 (In Russian).

Bangham, R. V. and J. R. Adams (1954): A survey of the parasites of freshwater fishes from the mainland of British Columbia. J. Fish. Res. Board Can., 11(6), 673708.

Bell, G. R. and L. Margolis (1976): The fish health program and the occurrence of fish diseases in the Pacific region of Canada. Fish Pathol., 10(2), 115-122.

Foerster, R. E. (1968): The Sockeye Salmon, Oncorhynchus nerka. Fish. Res. Board Can. Bull., 162, $\mathrm{xv}+422 \mathrm{pp}$.

FrENCH, R. R. (1965): Visceral adhesions in high-seas salmon. Trans. Amer. Fish. Soc., 94, 177-181.

Ko, R. C. and J. R. Adams (1969): The development of
Philonema oncorhynchi (Nematoda: Philometridae) in Cyclops bicuspidatus in relation to temperature. Can. $J$. Zool., 47, 307-312.

Konovalov, S. M. (1971): Differentiation of Local Populations of Sockeye Salmon Oncorhynchus nerka (Walbaum). "Nauka" Publ. House, Leningrad, 229 p. (Transl. from Russian by L. V. SAGEN, University of Washington Publications in Fisheries, New Ser., Vol. 6, University of Washington Press, Seattle, 1975).

Koo, T. S. Y. (1962): Age designation in salmon. In Studies of Alaska Red Salmon, T. S. Y. Koo (ed.). University of Washington Publications in Fisheries, New Ser., Vol. 1, University of Washington Press, Seattle, pp. 37-48.

Kuitunen-Ekbaum, E. (1933): Philonema oncorhynchi nov. gen. et spec. Contrib. Can. Biol. Fish., New Ser., 8(4), 71-75.

MARGOLIS, L. (1963): Parasites as indicators of the geographical origin of sockeye salmon, Oncorhynchus nerka (Walbaum), occurring in the North Pacific Ocean and adjacent seas. Int. North Pacific Fish. Comm., Bull., No. 11, 101-156.

MARGOLIS, L. (1970): Nematode diseases of marine fishes. In A Symposium on Diseases of Fishes and Shellfishes, S. F. SNiEszko (ed.). Amer. Fish. Soc. Spec. Publ. No. 5, pp. 190-208.

Margolis, L. (1982): Parasitology of Pacific salmon-an overview. In Aspects of Parasitology, E. MeERovitch (ed.). McGill University, Montreal, pp. 135-226.

OsaKo, M. (1973): Differentiation of mature and immature sockeye salmon caught by research vessels in May. Fisheries Agency of Japan, Far Seas Fish. Res. Lab., Shimizu, Japan. Unpubl. Manuscr (In Japanese).

Platzer, E. G. and J. R. Adams (1967): The life history of a drancunculoid, Philonema oncorhynchi, in Oncorhynchus nerka. Can. J. Zool., 45(1), 31-43.

TAKAGI, K. (1961): The seasonal change of gonad weight of sockeye and chum salmon in the North Pacific Ocean, especially with reference to mature and immature fish. Bull. Hokkaido Reg. Fish. Lab., (23), 17-34 (In Japanese with English summary).

TAKAGI, K. (1975): A non-selective salmon gillnet for research operations. Int. North Pacific Fish. Comm., Bull., No. 32, 13-41. 